\section{A cost-effective patient plan}

Now is the time for practices to examine all their overheads and reduce costs where possible. Everything from practice consumables to accountancy services are up for grabs, and one of the biggest single overheads in practice will be dental plan administration fees, so now's the time to take action and prepare for the future.

Ask yourself:

- Am I paying over the odds?

- Am I paying for services I don't want or ever use?

- Are any short-term offers going to help me in the long run?

- Am I getting the right level of service to meet my needs?

Patient Plan Direct offers permanently low fees to all clients by not including any unnecessary extras. It's a cost-effective patient plan with the highest standard of customer service and plan support.

If you want to save up to $£ 150,000$ over five years, while maintaining the control over your business and income, now is the time to speak to Patient Plan Direct. A switch is easy and simple - particularly if you ask your current provider for a transfer using the Pay. UK and Bacs-approved Bulk Change Scheme specifically.

Email info@patientplandirect.co.uk or call 03448486888 and Patient Plan Direct can guide you through the steps to see you permanently reduce your plan administration fees. Alternatively visit www.patientplandirect.com for more information.

\section{RPDs that patients prefer}

Solvay Dental 360 is proud to announce that a recent clinical study has demonstrated that removable partial dentures (RPDs) constructed with Ultaire AKP significantly improve oral health-related quality of life.

Ultaire AKP is a high-performance,

biocompatible polymer that has been custom developed for the fabrication of RPDs. It fits seamlessly into the digital workflow to produce RPDs with outstanding accuracy for increased comfort and fit.

The REFRAME study confirmed that RPDs made from Ultaire AKP provide a previously unattainable level of performance and patient satisfaction when compared to chrome cobalt and four out of five patients prefer them.
For RPDs that patients prefer, contact Solvay Dental 360 now!

Visit Solvay Dental 360 on stand J55 at the BDCDS 2020. For information about Ultaire AKP, plese visit www.solvaydental360.com.

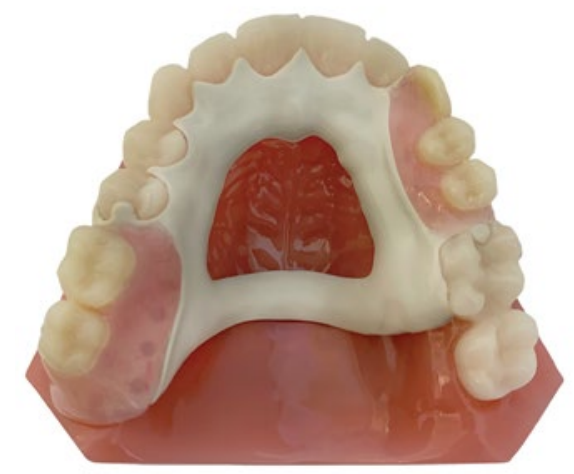

\section{Getting back to business}

As we all look forward to a time when we can start returning to normal, it's vital that you have access to the right information and support to help you get back to business.

The British Dental Conference and Dentistry Show 2020 will deliver a diverse lecture programme to help all members of the dental team take the next steps. Sessions will offer business advice and insight into the latest clinical techniques, with moderated debates and discussions providing a platform for colleagues to share ideas and concerns.

The extensive trade floor will also provide a place for delegates to source new products and technologies to streamline their processes and enhance

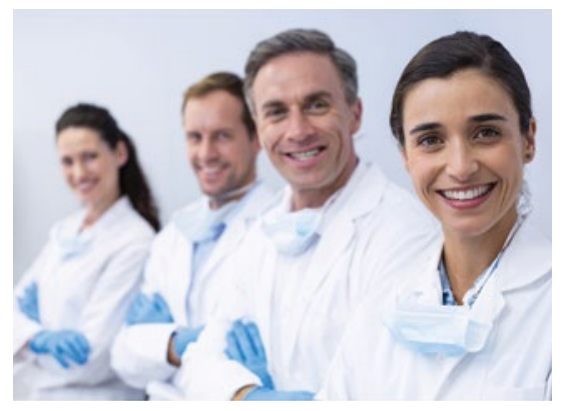

cost-efficiencies ready for getting back to business.

Register online for free today.

The British Dental Conference and Dentistry Show 2020 - 11 and 12 September - Hall 5, Birmingham NEC, co-located with DTS.

For more information, visit www. thedentistryshow.co.uk, call 02073485270 or email dentistry@closerstillmedia.com.

\title{
Helping function to return quickly
}

For patients that have undergone restorative treatment, post-operative discomfort can be an issue, but with the Scotchbond Universal Adhesive from 3M Oral Care patients can benefit from virtually no sensitivity, helping function to return quickly.

Together with a reliable bond strength that ensures ongoing durability and an aesthetic outcome, patients get the very best results when you use Scotchbond
Universal Adhesive from 3M.

As for you, the material has been designed to adapt to the way that you work so that you can deliver fast, reliable bonding with every use - smiles all round.

So, what are you waiting for? Get in touch now!

For more information, call 0800626578 or visit www.3M.co.uk/Dental.

$3 \mathrm{M}$ and Scotchbond are trademarks of the 3M Company. 